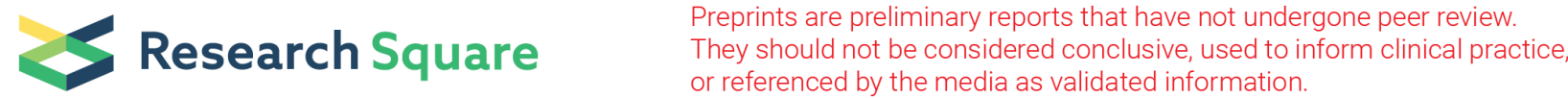

\section{Application of Multi-Attribute Decision-Making Methods for the Selection of Conveyor}

\section{Satyam Fulzele ( $\nabla$ fulzelesatyam@gmail.com )}

MIT Maharashtra Academy of Engineering

\section{Satywan Khatke}

MIT Maharashtra Academy of Engineering

Shubham Kadam

MIT Maharashtra Academy of Engineering

Avinash Kamble

MIT Maharashtra Academy of Engineering

\section{Research Article}

Keywords: Selection of conveyor, Analytical hierarchy process, Technique of Order Preference by Similarity to Ideal Solution, Compromise Ranking Method, Deng's Similarity Based Method

Posted Date: February 3rd, 2022

DOI: https://doi.org/10.21203/rs.3.rs-1033410/v2

License: (c) (1) This work is licensed under a Creative Commons Attribution 4.0 International License. Read Full License 


\section{Abstract}

In the present time of innovation, conveyor assume an exceptionally indispensable part and have huge significance for material handling in different enterprises. A conveyor is essentially utilized for moving any sort of material from one area to other. It is made with nearer precisions, hence the expense related with manufacturing is additionally high. In this manner, it should work with better productivity. The choice of the best conveyor is a crucial activity for designers. Designers need to recognize different variables that will influence the functionalities of the conveyor system to limit bottlenecks in the system. Therefore, an efficient methodology should be accomplished for the conveyor selection. Subsequently, the current work aims to the selection process of the best option for conveyor by using four decision making methods such as analytical hierarchy process, technique of order preference by similarity to ideal solution, compromise ranking method and Deng's similarity based method. The selection is done among four alternatives based on six attributes viz: fixed cost each hour, variable cost each hour, conveyor speed, product width, product weight and flexibility. The analytical hierarchy process is used to determine weights of the attributes based on relative importance of each attribute. It is also observed that A3 conveyor is best suitable conveyor. Hence the above proposed strategies help decision-makers to examine and choose the best conveyor by considering the rank obtained of the alternatives.

\section{Introduction}

Material handling conveyors are the backbone of today's industry now a days. This comprises of item arranging, flow and interacting the management, resource assignment, client conveyance, control and the executives of inventories, and after-deals supports and sales. If appropriate planning of material handling is done the delivery time will be minimized, it leads to lower overall expenses of manufacturing and improves customer service and reduces inventory cost. In India, about $80 \%$ of material handling is done by conveyors in most of the industries. The worldwide transport framework market size is projected to arrive at USD 10.6 billion by 2025, from an expected worth of USD 8.8 billion in 2021 . Thus, various processing and manufacturing plants are improving the performance of conveyor systems. Therefore, best conveyor must be chosen to reduce impact and wear of the conveyor and thereby increasing durability and strength. The following Figure 1 shows a typical material handling conveyor.

Hoshimov A. et al. [1] expressed the significance and utilizations of transports and examined a few tests on materials of a transport. This paper contains data about complex material and segment testing of transport lines which are utilized for its mathematical examinations. The Paper likewise contains the depiction of techniques utilized for user defined characterized material models and working of mathematical models. Material tests incorporate deciding of mechanical properties of elastic cover employs, material fortifications, and material utilizes with contiguous elastic. Segment tests incorporate uniaxial strain, biaxial pressure, twisting, and effect trial of complete transport lines.

\section{Literature Survey}


Various researchers are working in the field of various operational research activities to optimize various industrial processes. There are great kinds of literature available on the application of MADM techniques to achieve optimum solutions among various attributes and alternatives. In this section, some recent studies are done for the related research work.

Chaitanya and Srinivas [2] concerned design and manufacturing attributes for selecting the material, appropriate material selection becomes a very critical activity for designers. In the current journal, the utilization of MADM technique is experimented on the piston material determination for the optimal design procedure. Comparative investigation of attributes and alternative weights is done. This examination is directed to show the consistency in execution score ranking order as the attribute weights for each options change. The current issue is settled by ENTROPY and AHP strategies. Emovon and Oghenenyerovwho [3] introduced a deliberate survey of the utilization of the MADM technique in material choice. The consequences of the examination showed the accompanying, the crossover strategy which is the blend of at least two MADM strategies is the most practical procedure for material choice in all application regions recognized; the country with the most noteworthy use of MADM technique in India. It very well may be inferred that the MADM method is an exceptionally helpful technique in choosing material for various domains.

Devarakonda et al. [4] determined appropriate material assumes a key and crucial part in product design and development as every material has singular attributes that contribute numerous viewpoints to suit the specific application. This paper presents the choice of Magnesium alloy material to use in car wheel applications utilizing MADM techniques. The impact of weighting factors has additionally been examined. This work is settled by AHP, TOPSIS, and ENTROPY techniques. Tamboli et al. [5] expressed relatively large number of journal-bearing materials are available and only few will be possible to be used due to conflicting requirements. Hence, optimum selection of material is needed considering most requirements. A data matrix for various materials (alternatives) and their attributes is developed. The ideal choice is accomplished by applying notable MADM strategies. The outcomes concur for every strategy. The material for journal bearing is chosen by AHP and TOPSIS techniques.

Zulqarnain et al. [6] stretched the fuzzy TOPSIS strategy to neutrosophic fuzzy TOPSIS and demonstrate the exactness of the technique by clarifying the MCDM issue with single-esteemed neutrosophic data and utilize the technique for provider determination in supplier selection in the production industry. Verma et al. [7] proposed an MCDM methodology for evaluation and determination of material handling equipment for small-scale industry in Punjab. Two-stage is utilized for getting weights to different criteria and for their ranking empowering us to get more dependable outcomes needed for the selection of suitable material handling equipment. Komatina et al. [8] presented the concept of applying MADM methods through the fundamental stages. Also, the paper presents the classification of exact decision-making strategies. Specific attention has been paid to the analysis of methods of MADM methods, and their application in the selection of process equipment in various fields of industry. 
From the above literature study, it is observed that numerous scientists have dealt with strategies for finding the best optimum solution for their problem statements, but no researchers had worked on the conveyor selection for material handling in process industries using MADM methods such as AHP, TOPSIS, VIKOR and Deng's method. Therefore, in the current work, the attempt is made to track down the ideal ranking by above proposed techniques among six attributes viz: fixed cost each hour, variable cost each hour, conveyor speed, product width, product weight and flexibility and four alternative conveyors $A 1, A 2, A 3, A 4$.

\section{Methodology}

The current research work of selection of conveyor is successfully executed in four steps:

1. Identify attributes/criteria and available alternatives.

2. Rank the alternatives by using four selected MADM methods viz.: AHP, TOPSIS, VIKOR and Deng's similarity-based method.

3. Compare the results of rankings obtained from the selected MADM techniques.

4. Select best optimum alternative from the given alternatives.

The following sequence diagram represents the methodology done for the selection of conveyor as portrait in Figure 1.

\section{Madm Methods}

\subsection{AHP method}

Taherdoost [9] stated that Analytical Hierarchy Process is extremely valuable way to deal with complex selection issues. AHP break downs a decision-making issue into levels of orders of the goal, attributes and choices. Pacemska et al. [10] stated that AHP focuses on the general significance of a rundown of attributes through pair-wise correlations among the variables by applicable specialists with the assistance of nine-point scale. It permits the utilization quantitative as well as qualitative attributes in assessment.

The fundamental step by step methodology of AHP utilizing geometric mean method is as per the following,

\section{Step 1}

Recognize the target and assessment attributes. Make a progressive construction with a target at the high level, the attributes at the centre level and the options at the base level.

\section{Step 2}


Foster a pair-wise relation among the attributes with the assistance of nine-point scale of relative significance as characterized in Table 1. of relative significance concerning objective. A diagonal matrix attributes must always be assigned with value 1. Accepting $M$ attributes, the pair-wise correlation of attributes i with attribute $\mathbf{j}$ gives a matrix $\mathrm{BM} \times \mathbf{M}$ where, aij signifies the relative significance of attribute $\mathrm{i}$ concerning property $\mathbf{j}$. inside the matrix, $\mathbf{b i j}=\mathbf{1}$ once $\mathbf{I}=\mathbf{j}$ and $\mathbf{b j i}$. Track down the general standardized weight (Wj) of each criterion by calculating the mean of $\mathrm{i}^{\text {th }}$ row and normalizing the geometric mean for rows inside the correlation matrix.

The geometrical mean strategy for AHP is utilized to search out the overall Standardize weights of the criteria because of its effortlessness and effectiveness to search out the most extreme Eigenvalue and to downsize the irregularity in arrangement.

$\mathrm{GM}_{\mathrm{j}}=\left[\Pi \mathrm{b}_{\mathrm{ij}}\right]^{1 / \mathrm{M}}\left[\right.$ Formula for geometric mean calculation $\left.\left(\mathrm{GM}_{\mathrm{n}}\right)\right] \ldots(1)$

$\mathrm{W}_{\mathrm{j}}=\frac{\mathrm{GM}}{\Sigma \mathrm{GMj}}\left[\right.$ Formula for weight calculation $\left.\left(\mathrm{W}_{\mathrm{j}}\right)\right] \ldots(2)$

\section{Step 3}

Check or derive the consistency ratios

Let, $A_{1}=$ pair wise comparison matrix,

$A_{2}=$ weight of attributes,

$A_{3}=A_{1}{ }^{*} A_{2}$ and $A_{4}=A_{3} / A_{2} \ldots$ (3)

$\lambda_{\max }=A 4 / M$ i.e., average of matrix A4, where $M=$ Size of matrix ... (4)

$\mathrm{Cl}=\frac{(\lambda \max -M)}{(M-1)} \ldots$

$\mathrm{CR}=\mathrm{Cl} / \mathrm{RI} \ldots(6)$

Compute consistency ratio and it should be not exactly or equivalent to 0 , then, at that point just it is worthy and there is a decent consistency in decisions and choice matrix is correct else change in choice matrix and repeat from step 2 .

\section{Step 4}

Calculate the Standardize weight matrix for each criterion.

\section{Step 5}

The following step is to ask the in general presentation scores for the options by increasing the overall standardized weight (Wj) of every criterion (got in Step 2) with its comparing standardized weight value 
for every option (got in Step 3) and making addition over every one of the attributes for each option. In the event that quantitative data are not accessible, these values should be changed over into fuzzy scores. By utilizing fuzzy pure maths, the value of the criteria is frequently first chosen as linguistic terms, changed over into relating fuzzy scores then, at that point changed over to the fuzzy scores.

\section{Step 6}

Calculate the final Rank and compare the choices and find the best choice.

\subsection{TOPSIS method}

Çelikbilek and Fatih [11] expressed that this strategy follows the idea that the chosen option ought to have the base Euclidean distance from the positive ideal arrangement and most extreme from the negative ideal arrangement. TOPSIS takes advantage of positive-ideal arrangement (PIS) and negativeideal arrangement (NIS) of various attribute issues to rank the alternatives. Zulqarnain et al. [12] stated that the TOPSIS along these offers the response that is not just nearest to theoretically best, that is additionally the farthest from the theoretically bad. This gives us the best solution as well as rankings of options expressing the significance of TOPSIS for assessment and ranking.

The principal system of the TOPSIS technique for determination of the best option from among those accessible is depicted below,

\section{Step 1}

Create the Standardize decision matrix.

$r_{i j}=\frac{x_{i j}}{\left(x_{i j}^{2}\right)}$ for $\mathrm{i}=1 \ldots \mathrm{m} ; \mathrm{j}=1 \ldots \mathrm{n} . . .(7)$

\section{Step 2}

Create the weighted Standardize decision matrix.

Let us have array of weights for each attribute $W_{j}$ for $j=1 \ldots . n$. Take a product of each column of the Standardize decision matrix by its related weight.

$V_{i j}=W_{j} * r_{i j} \cdots$

\section{Step 3}

Detect ideal best (PIS) and ideal worst (NIS) solutions

Positive ideal (best) solution: (Highest value for beneficial and lowest for non-beneficial attribute) 
Negative ideal (worst) solution: (Lowest value for beneficial and Highest for non-beneficial attribute)

\section{Step 4}

Compute the separation measure.

Positive separation measures

$\mathrm{S}_{\mathrm{i}}^{+}=\sqrt{\sum\left(V_{j}^{+}-V_{i j}\right)^{2}} \ldots$

Negative separation measures

$\mathrm{S}_{\mathrm{i}}^{-}=\sqrt{\sum\left(V_{j}^{-}-V_{i j}\right)^{2}} \ldots$

\section{Step 5}

Compute the relative nearness to the desired ideal solution.

$\mathrm{P}_{\mathrm{i}}=\frac{S_{i}^{-}}{\left(S_{i}^{-}+S_{i}^{+}\right)} \ldots$

\section{Step 6}

Rank the preference order.

In this way, the choices are finally positioned in plummeting order and the ranking is acquired. The primary rank got is the nearest answer for ideal arrangement and farthest from negative ideal arrangement. Additionally, the last rank acquired is the farthest arrangement from ideal arrangement and nearest to the negative ideal arrangement.

\subsection{VIKOR method}

Mardani et al. [13] stated that the VIKOR technique or the compromise ranking strategy discovers answer for an issue with conflicting attributes can permit the decision-makers to arrive at an official choice. The compromise arrangement might be a plausible arrangement that is closest to the ideal arrangement, and compromise implies an understanding set up by common concession. Sajja [14] mentioned that the VIKOR technique was created as a multi-attribute decision-making strategy to tackle discrete choice issues with non-commensurable and clashing attributes. This strategy centers around ranking and choosing from a gathering of choices inside the presence of clashing attributes, is to help decisionmakers to arrive at a definitive objective.

The fundamental procedure of the VIKOR strategy is as per the following,

\section{Step 1}


To identify objective, and to calculate best $\left(\mathrm{X}_{i}^{+}\right)$and worst $\left(\mathrm{X}_{\mathrm{i}}^{-}\right)$values among all attributes.

\section{Step 2}

Calculate the optimal and inferior solution of schemes comprehensive evaluation.

$\mathrm{E}_{\mathrm{i}}=\sum_{j=1}^{M} \frac{w_{j} *\left(\left(m_{i j}\right)_{\max }-m_{i j}\right)}{\left(\left(m_{i j}\right)_{\max }-\left(m_{i j}\right)_{\min }\right)} \ldots$

$\mathrm{F}_{\mathrm{i}}=\operatorname{Max}$ of $\sum_{j=1}^{M} \frac{w_{j} *\left(\left(m_{i j}\right)_{\max }-m_{i j}\right)}{\left(\left(m_{i j}\right)_{\max }-\left(m_{i j}\right)_{\min }\right)} \ldots$

\section{Step 3}

Calculate the value of $(P)$ interest's ratio brought by scheme.

$\mathrm{P}=\frac{v *\left(E-E_{\min }\right)}{\left(E_{\max }-E_{\min }\right)}+(1-v) * \frac{\left(F-F_{\min }\right)}{\left(F_{\max }-F_{\min }\right)}$ where, the standard value of $v=0.5 \ldots$

\section{Step 4}

Arrange the alternatives according to values of interest ratio in the ascending order.

After the alternatives are arranged according to ranks, the first alternative is the best solution and the last alternative is the worst solution.

\subsection{Deng's Similarity-based method}

Deng [15] mentioned the recreation correlation with other remaining strategies, TOPSIS has the fewest rank which is not quite the same as the leftover techniques. To conquer this Deng (2007) presented the idea of other gradient to address the contention of other in numerous attribute examination issue.

The step by step procedure for Deng's Similarity Method is portrayed below,

\section{Step 1}

Decide the overall significance of various attributes regarding the goal. Make a pair-wise correlation matrix utilizing a nine-point scale of relative significance. This step is clarified above in AHP strategy (4.1) solution (step1).

\section{Step 2}

Normalizing the decision matrix through Euclidean normalization.

$r_{i j}=\frac{x_{i j}}{\left(x^{2}\right)}$ 


\section{Step 3}

Make the weighted standardized choice matrix. Expect that we have a array of weights for every attribute Wj. Take a product of every column of the standardized choice matrix by its related weight.

$\mathrm{V}_{\mathrm{ij}}=\mathrm{W}_{\mathrm{j}} \mathrm{r}_{\mathrm{ij}} \ldots$

\section{Step 4}

Determine Positive ideal solutions (PIS) and Negative ideal solutions (NIS) as discussed in TOPSIS method $(4.2-$ step 3$)$.

\section{Step 5}

Conflict index between alternative and PIS and NIS

The degree of clash between alternative $\left(A_{i}\right)$ and $\left(I^{+}\right) \&\left(I^{-}\right)$is expressed by:

$\cos \theta_{i}^{+}=\frac{y_{i j} * I^{+}}{\sqrt{\sum y_{i j}^{2} * \sum\left(I_{j}^{+}\right)^{2}}} \ldots$

$\cos \theta_{i}^{-}=\frac{y_{i j} * I^{-}}{\sqrt{\sum y_{i j}^{2} * \sum\left(I_{j}^{-}\right)^{2}}} \ldots$

\section{Step 6}

As per the degree of the clash between the alternative and the PIS and NIS, the degree of similarity of the alternative between alternative $\left(A_{i}\right)$ and $\left(I^{+}\right) \&\left(I^{-}\right)$can be expressed as follows

$\mathrm{S}_{\mathrm{i}}^{+}=\frac{\cos \left(\theta_{i}^{+}\right) * A_{i}}{I_{j}^{+}} \ldots$

$\mathrm{S}_{\mathrm{i}}^{-}=\frac{\cos \left(\theta_{i}^{-}\right) * A_{i}}{I_{j}^{-}} \ldots$

\section{Step 7}

Calculating overall index for every alternative across all attributes

$\mathrm{P}_{\mathrm{i}}=\frac{S_{i}^{+}}{\left(S_{i}^{+}+S_{i}^{-}\right)} \ldots$

\section{Step 8}


Rank the choices according to the overall index in descending order.

\section{Conveyor Selection Problem Statement}

Material handling conveyors plays a very vital role in most of industries now a days. Industries spends millions of dollars for conveyor. Therefore, proper conveyor must be selected for the material handling. The MADM methods have been applied for selection of material, thus selection process will be more accurate. The present case study consists of six attributes i.e. fixed cost each hour (FC), variable cost each hour (VC), conveyor speed (CS), product width (PW), product weight (W) and flexibility (F) and four alternative conveyors i.e. A1, A2, A3 and A4 as characterized in Table 4. Among these six attributes CS, PW, W and F are beneficial attributes (displayed in green font) while FC and VC are non-beneficial attributes (displayed in red font). The qualitative data is as follows:

\section{Solutions Using Madm Methods \\ 6.1. Solution by AHP method}

\section{Step 1}

The goal is to select the best conveyor among the given alternatives.

\section{Step 2}

Create a correlation matrix among the criteria and calculate geometric mean and weights.

Table 3. represents correlation matrix.

Geometric mean calculation by using eq. (1)

$\mathrm{GM}_{1}=(1 * 2 \star 2 \star 3 * 3 * 2)^{1 / 6}=2.040$

$\mathrm{GM}_{2}=(1 / 2 * 1 * 2 * 3 * 2 * 2)^{1 / 6}=1.513$

$\mathrm{GM}_{3}=\left(1 / 2 \star 1 / 2 \star 1 * 1 / 3 * 1 / 5^{\star} 1 / 3\right)^{1 / 6}=0.421$

$\mathrm{GM}_{4}=(1 / 3 \star 1 / 2 \star 3 \star 1 * 1 / 3 * 1 / 2)^{1 / 6}=0.618$

$\mathrm{GM}_{5}=(1 / 3 * 1 / 2 * 5 * 3 * 1 * 2)^{1 / 6}=1.308$

$\mathrm{GM}_{6}=(1 / 2 \star 1 / 2 \star 3 * 2 * 1 / 2 * 1)^{1 / 6}=0.953$

Sum of geometric mean $\left(\Sigma \mathrm{GM}_{\mathrm{j}}\right)=6.852$

Weight calculation by using eq. (2) 
$W_{1}=0.298, W_{2}=0.221, W_{3}=0.061, W_{4}=0.090, W_{5}=0.191, W_{6}=0.139$

\section{Step 3}

Check the consistency (weights correct or not).

$A_{1}=\left[\begin{array}{cccccc}1 & 2 & 2 & 3 & 3 & 2 \\ 1 / 2 & 1 & 2 & 3 & 2 & 2 \\ 1 / 2 & 1 / 2 & 1 & 1 / 3 & 1 / 5 & 1 / 3 \\ 1 / 3 & 1 / 3 & 3 & 1 & 1 / 3 & 1 / 2 \\ 1 / 3 & 1 / 2 & 5 & 3 & 1 & 2 \\ 1 / 2 & 1 / 2 & 3 & 2 & 1 / 2 & 1\end{array}\right] A_{2}=\left[\begin{array}{l}0.298 \\ 0.221 \\ 0.061 \\ 0.090 \\ 0.191 \\ 0.139\end{array}\right]$

$\mathrm{A}_{3}=\mathrm{A} 1^{\star} \mathrm{A} 2=\left[\begin{array}{l}1.983 \\ 1.423 \\ 0.435 \\ 0.580 \\ 1.256 \\ 0.858\end{array}\right] \mathrm{A}_{4}=\left[\begin{array}{l}6.663 \\ 6.443 \\ 7.087 \\ 6.438 \\ 6.583 \\ 6.170\end{array}\right]$

Now, the maximum Eigen value is calculated by the average of matrix A4 by using eq. (4)

$\lambda_{\max }=\mathrm{A}_{4} / 6=6.564$

$\mathrm{Cl}=\frac{(\lambda \max -M)}{(M-1)}=\frac{6.564-6}{6-1}=0.113$...by using eq. (5)

$\mathrm{CR}=\frac{C I}{R I}=0.113 / 1.25=0.090 \ldots$...by using eq. $(6)$

(Value of RI is taken from Table 2. For six attributes)

As the $\mathrm{CR} \geq 0$ Hence, the decision matrix is right and above weights are correct.

\section{Step 4}

Calculation of normalized weights.

\section{Step 5}


Calculate overall performance index by multiplying weight for each row of alternatives as displayed in below calculation and it is displayed by Table 4 .

Overall performance index (OPI),

$A 1=(1 \star 0.298)+(0.978 \star 0.221)+\left(0.923^{\star} 0.061\right)+(0.5 \star 0.090)+(0.5 \star 0.191)+(0.780 \star 0.139)=0.819$

$A 2=(0.870 * 0.298)+(1 * 0.221)+(1 * 0.061)+(0.667 * 0.090)+(0.5 * 0.191)+(1 * 0.139)=0.836$

$A 3=(0.889 * 0.298)+(0.978 * 0.221)+(0.846 * 0.061)+(1 * 0.090)+(1 * 0.191)+(1 * 0.139)=0.953$

$A 4=(0.833 * 0.298)+(0.957 * 0.221)+(0.769 * 0.061)+(0.833 * 0.090)+(0.75 * 0.191)+(0.780 * 0.139)=$ 0.833

Arrange the alternatives in descending order.

Thus, the ranking is A3-A2-A4-A1 and it is found that $\mathbf{A} 3$ conveyor is best.

\section{Step 6}

Compute Ranking of alternatives as displayed in Table 5.

\subsection{Solution by TOPSIS method}

\section{Step 1}

Create the Standardize decision matrix, using eq. (7).

\section{Step 2}

Construct the weighted normalized decision matrix, using eq. (8) as displayed in Table 6.

\section{Step 3}

Determine ideal best (PIS or $\mathrm{V}_{j}^{+}$) and ideal worst (NIS or $\mathrm{V}_{\mathrm{j}}^{-}$) solutions as displayed in Table 7.

\section{Step 4}

Calculate Positive $\left(\mathrm{S}_{\mathrm{i}}^{+}\right)$and Negative $\left(\mathrm{S}_{\mathrm{i}}^{-}\right)$separation measures using eq. (9) and eq. (10) respectively as displayed in Table 8.

\section{Step 5}

Calculate the relative nearness to the ideal solution ( $\mathrm{Pi})$, using eq. (11) and rank the order of conveyors as displayed in Table 9. 
From the above table the rank obtained is A3-A4-A1-A2 and the conveyor A3 is the best one.

\subsection{Solution by VIKOR method}

\section{Step 1}

To identify objective, and to calculate best $\left(\mathrm{X}_{\mathrm{i}}^{+}\right)$and worst $\left(\mathrm{X}_{\mathrm{i}}^{-}\right)$values among all attributes.

\section{Step 2}

Calculate the optimal and inferior solution of schemes comprehensive evaluation, using eq. (12) and eq. (13) as displayed in Table 10.

\section{Step 3}

Calculate the value of interest ratio $(P)$ brought by scheme, using eq. (14) as displayed in Table 11.

\section{Step 4}

Rank the alternatives according to values of interest ratio in the ascending order, as displayed in Table 12.

From the above table, the rank obtained among conveyor alternatives is $\mathbf{A} \mathbf{3}-\mathbf{A} \mathbf{1}-\mathbf{A} \mathbf{2}-\mathbf{A} \mathbf{4}$ and $\mathbf{A} \mathbf{3}$ conveyor is best suitable.

\subsection{Solution by Deng's Similarity based method}

\section{Step 1}

Determine the relative importance of different attributes regarding the objective as discussed in the AHP method (section 6.1, step 2)

\section{Step 2}

Normalizing the decision matrix through Euclidean normalization, using eq. (15).

\section{Step 3}

Create the weighted normalized decision matrix, using eq. (16) as displayed in Table 13.

\section{Step 4}

Detect Positive ideal solutions (PIS) and Negative ideal solutions (NIS) as discussed in the TOPSIS method (section 6.2, step 3).

\section{Step 5}

Conflict index between alternative and PIS and NIS, using eq. (17) and (18). 


\section{Step 6}

Calculate the degree of similarity of the alternative between alternative $\left(A_{i}\right)$ and $\left(I^{+}\right) \&\left(I^{-}\right)$, using eq. (19) and (20).

\section{Step 7}

Calculating overall index (Pi) for every alternative across all attributes, using eq. (21) and rank the alternatives according to the overall index in the descending order, as displayed in Table 14.

From the above table, the ranking among the choices of conveyor is A3-A4-A1-A2 and again the conveyor A3 is best appropriate.

From the above assessments of alternatives of conveyors, the A3 conveyor is found as the best choice for conveyor choice for the given contextual investigation. Further, distinct values of attributes are utilized in this work for looking at the options of conveyor in satisfying every one of the six attributes. In this way, the technique gives a more practical decision to conveyor selection process.

\section{Results And Discussion}

In the present work used four MADM methods viz. AHP, TOPSIS, VIKOR and Deng's similarity-based techniques to detect best suitable conveyor for material handling. The four alternatives of conveyors are examined with respect to their six specified attributes. The rank obtained by the selected methods is displayed in Table 15 that summarizes ranking performances of conveyor obtained by using selected four methods. The ranking gained from the given methods can be better examined which can involve the decision-maker to assess better preference. The rank obtained by given methods gives 'A $\mathbf{3}$ ' as the most suitable conveyor.

The similar ranking of the conveyor is acquired by utilizing four MADM techniques as displayed in Fig. 2, which shows that first rank from every technique coming is ' $\mathrm{A} 3$ ' conveyor which is the best chosen conveyor. The present work discusses about the taken methods and it helps to approach a best conveyor. These methods can also be applicable for complex engineering and general applications.

\section{Conclusions And Future Scope}

The evaluation of available conveyor and selection of best suitable conveyor is very crucial and important decision for any process industry. The several more conveyors with different properties and specifications are also available, but selecting correct one among the conflicting attributes is the complex task for every designer. The selection of improper conveyor can directly or indirectly affect the productivity and efficiency of any process industry. Thus, it is important to select the best conveyor for better material handling. The present work shows the easy and logical scientific study to guide any decision-maker for selecting any best alternative. The methodology done in the present work helps decision-maker to take qualitative decision. 
In the present work, four selected decision making methods viz: AHP, TOPSIS, VIKOR and Deng's similarity-based methods are used for solving the proposed problem. The AHP method is used for obtaining weights of all attributes and are applicable for the remaining methods as well. It is found from the ranks obtained using selected methods that A3 conveyor is the best suitable choice for material handling among the four alternatives. It is observed that ranking of conveyor has some deviation in the rankings due to different mathematical approaches used in the four methods. Finally, it is concluded that these methods are very helpful for making decision in complex problems. The problem can be further solved by other decision making methods for improvement and reliability. Also, the proposed methods can be employed for making the best decision in the other domains of engineering and general administration problems.

\section{Declarations}

\section{Ethical Standards statements:}

i. Ethical approval: I Satyam Fulzele agree and declare that this submission follows the policies of Soft Computing as outlined in the Guide for Authors and in the Ethical Approval.

ii. Funding details (In case of Funding): NA

iii. Conflict of interest: NA

iv. Informed Consent: I Satyam Fulzele have read and I understand the provided information and have had the opportunity to ask questions. I understand that my participation is voluntary and that I am free to withdraw at any time, without giving a reason and without cost. I understand that I will be given a copy of this consent form. I voluntarily agree to take part in this study.

\section{Authorship Contribution:}

Satyam Fulzele and Satywan Khatke conceived of the presented idea. Satyam Fulzele developed the theory and performed the computations. Satywan Khatke and Shubham Kadam verified the analytical methods. Dr. Avinash Kamble encouraged Satyam Fulzele to investigate study of conveyors and supervised the findings of this work. All authors discussed the results and contributed to the final manuscript.

\section{References}

[1] Hoshimov A., Rozzokov J. \& Rustamov A., (2018), "Industrial Conveyors", Taxonomy and Its Applications Journal, 8 (3), pp. 60-62.

[2] Chaitanya K. \& Srinivas K., (2019), "Sensitive Analysis on Selection of Piston Material Using MADM Techniques", Journal of Mechanical Engineering, 69 (4), pp. 45-56. 
[3] Emovon, I. \& Oghenenyerovwho 0., (2020), "Application of MCDM method in material selection for optimal design: A review", Results in Materials, 7 (4), pp. 1-55.

[4] Devarakonda, Kumar S. \& Suman K., (2014), "Selection of Magnesium Alloy by MADM Methods for Automobile Wheels", International Journal of Engineering and Manufacturing, 4 (2), pp. 31-41.

[5] Tamboli K., Sanghvi R. \& George, P., (2013), "Optimum selection of material for journal bearing using MADM methods", International Conference on Computer Aided Engineering, At Departnent of Mechanical Engineering, IIT Madras, India, pp. 1-6.

[6] Zulqarnain R., Xiao X., Saeed M., Smarandache F. \& Nadeem A., (2020), "Generalized Neutrosophic TOPSIS to Solve Multi-Criteria Decision-Making Problems", Neutrosophic Sets and Systems, 38, pp. 276292.

[7] Verma P., Kumar R. \& Goindi G., (2019), "Evaluation of Material Handling Using MCDM Techniques: A Case Study", book in Advances in Production and Industrial Engineering, Select Proceedings of ICETMIE, pp. 389-40.

[8] Komatina N., Ljepava, N. \& Danijela T., (2018), "The analysis procedure and application of MultiCriteria Decision-Making methods in selection of industry equipment", 3rd International Conference on Quality of Life, Center for Quality, Faculty of Engineering, University of Kragujevac, pp. 157-164.

[9] Taherdoost H., (2017), “Decision Making Using the Analytical Hierarchy Process (AHP), A Step by Step Approach", International Journal of Economics and Management Systems, 2, pp. 244-245.

[10] Pacemska, T., Lapevski, M. \& Timovski, R., (2014), "Analytical hierarchical process (AHP) method application in the process of selection and evaluation", International Scientific Conference, Goce Delcev University in Stip, Republic of Macedoni, pp. 374-380.

[11] Çelikbilek Y. \& Fatih T., (2020), "An in-depth review of theory of the TOPSIS method: An experimental analysis", Journal of Management Analytics, 7 (2), pp. 1-20.

[12] Zulqarnain R., Saeed M., Nadeem A., Dayan F. \& Ahmad B., (2020), "Application of TOPSIS Method for Decision Making", International Journal of Scientific Research in Mathematical and Statistical Sciences, 7 (2), pp. 76-81.

[13] Mardani A., Edmundas Z., Govindan K., Senin A. \& Jusoh A., (2016), "VIKOR Technique: A Systematic Review of the State of the Art Literature on Methodologies and Applications", Sustainability, 37(8), pp. 138.

[14] Sajja R., (2013), "VIKOR Method for multi criteria decision making in academic staff selection", Journal of Production Research and Management, 2(3), pp. 30-35. 
[15] Deng X. \& Deng Y., (2019), "D-AHP method with different credibility of information”, Soft Computing, 23(7), pp. 683-691.

\section{Tables}

Table 1. Nine-point scale of relative importance

\begin{tabular}{|c|c|c|}
\hline $\begin{array}{l}\text { Numerical } \\
\text { values of } \\
\text { importance }\end{array}$ & Verbal scale & Description \\
\hline 1 & Equal significance & Judgement favours both attributes equally \\
\hline 3 & $\begin{array}{l}\text { Moderate } \\
\text { significance }\end{array}$ & Judgement favours slightly one attribute \\
\hline 5 & Solid significance & Judgement favours strongly one attribute \\
\hline 7 & $\begin{array}{l}\text { Exceptionally solid } \\
\text { significance }\end{array}$ & One attribute is supported firmly over another \\
\hline 9 & $\begin{array}{l}\text { Outrageous } \\
\text { significance }\end{array}$ & $\begin{array}{l}\text { The proof supporting one characteristic over another is } \\
\text { of the greatest conceivable order of affirmation }\end{array}$ \\
\hline $2,4,6,8$ & $\begin{array}{l}\text { Immediate values } \\
\text { between above } \\
\text { values }\end{array}$ & $\begin{array}{l}\text { Absolute judgement cannot be given and a compromise } \\
\text { is required. }\end{array}$ \\
\hline
\end{tabular}

Table 2. Quantitative data for case study

\begin{tabular}{|lllllll|}
\hline Conveyors & $\begin{array}{l}\text { FC (in } \\
\text { lacs) }\end{array}$ & $\begin{array}{l}\text { VC (in } \\
\text { lacs) }\end{array}$ & $\begin{array}{l}\text { CS (feet per } \\
\text { minute) }\end{array}$ & $\begin{array}{l}\text { IW (in } \\
\text { Cms) }\end{array}$ & $\begin{array}{l}\text { W (in } \\
\mathbf{k g s})\end{array}$ & $\mathbf{F}$ \\
\hline A1 & 2 & 0.45 & 12 & 15 & 10 & $\begin{array}{l}\text { Very good } \\
(0.745)\end{array}$ \\
\hline A2 & 2.3 & 0.44 & 13 & 20 & 10 & $\begin{array}{l}\text { Excellent } \\
(0.955)\end{array}$ \\
\hline A3 & 2.25 & 0.45 & 11 & 30 & 20 & $\begin{array}{l}\text { Excellent } \\
(0.955)\end{array}$ \\
\hline A4 & 2.4 & 0.46 & 10 & 25 & 15 & $\begin{array}{l}\text { Very good } \\
(0.745)\end{array}$ \\
\hline
\end{tabular}

Table 3. Correlation matrix 


\begin{tabular}{lllllll} 
Attributes & $F C$ & $V C$ & $S C$ & $I W$ & $W$ & $F$ \\
\hline$F C$ & 1 & 2 & 2 & 3 & 3 & 2 \\
\hline$V C$ & $1 / 2$ & 1 & 2 & 3 & 2 & 2 \\
\hline$S C$ & $1 / 2$ & $1 / 2$ & 1 & $1 / 3$ & $1 / 5$ & $1 / 3$ \\
\hline$I W$ & $1 / 3$ & $1 / 3$ & 3 & 1 & $1 / 3$ & $1 / 2$ \\
\hline$W$ & $1 / 3$ & $1 / 2$ & 5 & 3 & 1 & 2 \\
\hline$F$ & $1 / 2$ & $1 / 2$ & 3 & 2 & $1 / 2$ & 1
\end{tabular}

Table 4. Normalized weighted matrix

\begin{tabular}{lllllll} 
Conveyor & \multicolumn{2}{l}{ Attributes } \\
\cline { 2 - 7 } & FC & VC & SC & IW & W & F \\
\hline$A 1$ & 0.298 & 0.216 & 0.057 & 0.045 & 0.095 & 0.109 \\
\hline$A 2$ & 0.259 & 0.221 & 0.061 & 0.060 & 0.095 & 0.139 \\
\hline$A 3$ & 0.265 & 0.216 & 0.052 & 0.090 & 0.191 & 0.139 \\
\hline$A 4$ & 0.248 & 0.211 & 0.047 & 0.075 & 0.143 & 0.109
\end{tabular}

Table 5. Ranking of alternatives

\begin{tabular}{lll} 
Alternative & OPI & Rank \\
\hline A1 & 0.819 & 4 \\
\hline A2 & 0.836 & 2 \\
\hline A3 & 0.953 & 1 \\
\hline A4 & 0.833 & 3 \\
\hline
\end{tabular}

Table 6. Weighted normalized decision matrix 


\begin{tabular}{lllllll} 
Conveyor & \multicolumn{6}{l}{ Attributes } \\
\cline { 2 - 7 } & FC & VC & SC & IW & W & F \\
\hline$A 1$ & 0.133 & 0.110 & 0.032 & 0.029 & 0.066 & 0.060 \\
\hline$A 2$ & 0.153 & 0.108 & 0.034 & 0.039 & 0.066 & 0.077 \\
\hline$A 3$ & 0.150 & 0.110 & 0.029 & 0.058 & 0.133 & 0.077 \\
\hline$A 4$ & 0.159 & 0.113 & 0.026 & 0.049 & 0.100 & 0.060
\end{tabular}

Table 7. Ideal best and Ideal worst values

\begin{tabular}{|lllllll|}
\hline Ideal best $\left(\mathrm{N}_{\mathrm{j}}^{+}\right)$ & 0.133 & 0.108 & 0.034 & 0.058 & 0.133 & 0.077 \\
\hline Ideal worst $\left(\mathrm{V}_{\mathrm{j}}^{-}\right)$ & 0.159 & 0.113 & 0.026 & 0.029 & 0.066 & 0.060 \\
\hline
\end{tabular}

Table 8. Positive $\left(\mathrm{S}_{\mathrm{i}}^{+}\right)$and Negative $\left(\mathrm{S}_{\mathrm{i}}^{-}\right)$separation measures

\begin{tabular}{|ll|}
\hline Si $^{+}$ & Si $^{-}$ \\
\hline 0.075 & 0.027 \\
\hline 0.072 & 0.023 \\
\hline 0.018 & 0.075 \\
\hline 0.048 & 0.038 \\
\hline
\end{tabular}

Table 9. Relative nearness to the ideal solution ( $\mathrm{Pi})$

\begin{tabular}{lll} 
Conveyor & Pi & Rank \\
\hline$A 1$ & 0.267 & 3 \\
\hline$A 2$ & 0.240 & 4 \\
\hline$A 3$ & 0.811 & 1 \\
\hline$A 4$ & 0.446 & 2
\end{tabular}

Table 10. Optimal and Inferior solutions 


\begin{tabular}{lllllllll} 
Conveyor & \multicolumn{2}{l}{ Attributes } \\
\cline { 2 - 9 } & FC & VC & SC & IW & W & F & Ei & Fi \\
\hline$A 1$ & 0.00 & 0.11 & 0.02 & 0.09 & 0.19 & 0.14 & 0.55 & 0.19 \\
\hline$A 2$ & 0.22 & 0.00 & 0.00 & 0.06 & 0.19 & 0.00 & 0.47 & 0.22 \\
\hline$A 3$ & 0.19 & 0.11 & 0.04 & 0.00 & 0.00 & 0.00 & 0.34 & 0.19 \\
\hline$A 4$ & 0.30 & 0.22 & 0.06 & 0.03 & 0.10 & 0.14 & 0.84 & 0.30
\end{tabular}

Table 11. Interest ratio $(P)$

\begin{tabular}{llll} 
Conveyor & $\boldsymbol{E}_{\boldsymbol{i}}$ & $\boldsymbol{F}_{\boldsymbol{i}}$ & $\boldsymbol{P}$ \\
\hline$A 1$ & 0.55 & 0.19 & 0.21 \\
\hline$A 2$ & 0.47 & 0.22 & 0.27 \\
\hline$A 3$ & 0.34 & 0.19 & 0.00 \\
\hline$A 4$ & 0.84 & 0.3 & 1.00 \\
\hline$E_{\text {max }}, F_{\text {max }}$ & 0.84 & 0.3 & \\
\hline$E_{\text {min }} F_{\text {min }}$ & 0.34 & 0.19 &
\end{tabular}

Table 12. Ranking of alternatives

\begin{tabular}{lll} 
Conveyor & $P$ & Rank \\
\hline A1 & 0.21 & 2 \\
\hline A2 & 0.27 & 3 \\
\hline$A 3$ & 0.00 & 1 \\
\hline$A 4$ & 1.00 & 4 \\
\hline
\end{tabular}

Table 13. Weighted normalized decision matrix 


\begin{tabular}{lllllll} 
Conveyor & \multicolumn{6}{l}{ Attributes } \\
\cline { 2 - 7 } & FC & VC & SC & IW & W & F \\
\hline$A 1$ & 0.133 & 0.110 & 0.032 & 0.029 & 0.066 & 0.060 \\
\hline$A 2$ & 0.153 & 0.108 & 0.034 & 0.039 & 0.066 & 0.077 \\
\hline$A 3$ & 0.150 & 0.110 & 0.029 & 0.058 & 0.133 & 0.077 \\
\hline$A 4$ & 0.159 & 0.113 & 0.026 & 0.049 & 0.100 & 0.060
\end{tabular}

Table 14. Overall performance index (Pi)

\begin{tabular}{lll} 
Conveyor & Pi & Rank \\
\hline A1 & 0.444 & 3 \\
\hline$A 2$ & 0.443 & 4 \\
\hline$A 3$ & 0.464 & 1 \\
\hline A4 & 0.452 & 2
\end{tabular}

Table 15. Ranking obtained by each method

\begin{tabular}{lllll} 
Alternatives & $\boldsymbol{A 1}$ & $\boldsymbol{A} 2$ & $\boldsymbol{A 3}$ & $\boldsymbol{A 4}$ \\
\hline AHP & 4 & 2 & 1 & 3 \\
\hline TOPSIS & 3 & 4 & 1 & 2 \\
\hline VIKOR & 2 & 3 & 1 & 4 \\
\hline Deng's & 3 & 4 & 1 & 2
\end{tabular}

Figures 
1. Identify attributes and alternatives

2. Find the rank of alternatives using AHP, TOPSIS, VIKOR and Deng's methods

3. Compare the results of rankings

4. Select best alternative from the given alternatives

\section{Figure 1}

Methodology: Methodology for the research work

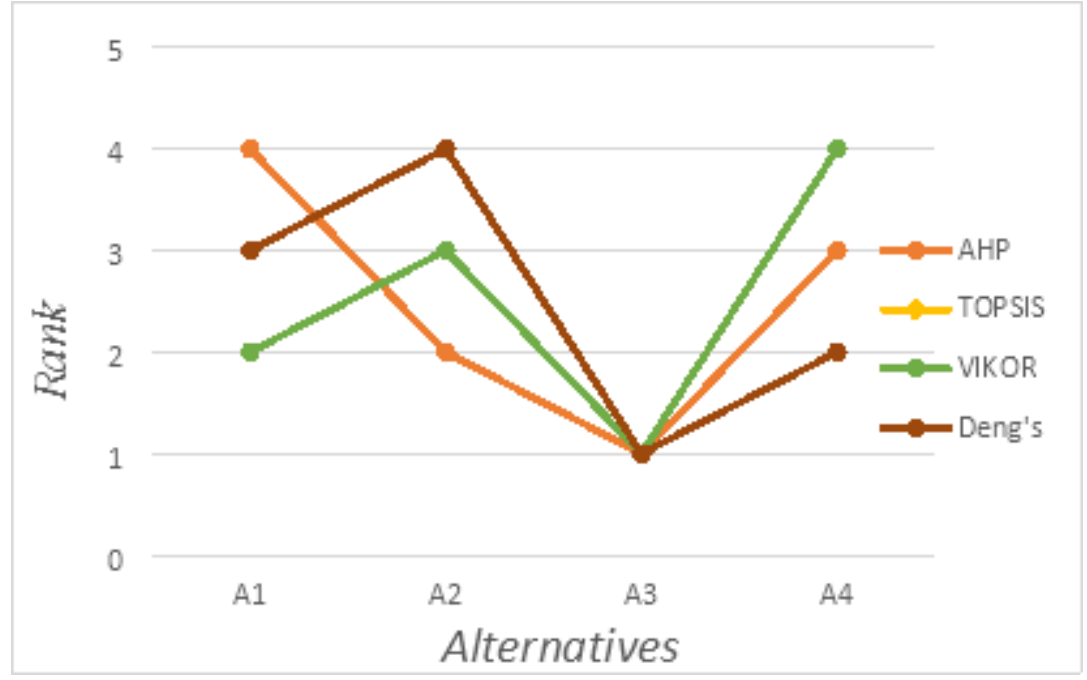

Figure 2

Comparison chart of Alternatives v/s Ranks: Final Conclusion of Research Work 